\title{
The liner shipping berth scheduling problem with transit times
}

Reinhardt, Line Blander; Plum, Christian E.M. ; Pisinger, David; Sigurd, Mikkel M.; Vial, Guillaume T.P.

Published in:

Transportation Research. Part E: Logistics and Transportation Review

Link to article, DOI:

10.1016/j.tre.2015.12.006

Publication date:

2016

Document Version

Peer reviewed version

Link back to DTU Orbit

Citation (APA):

Reinhardt, L. B., Plum, C. E. M., Pisinger, D., Sigurd, M. M., \& Vial, G. T. P. (2016). The liner shipping berth scheduling problem with transit times. Transportation Research. Part E: Logistics and Transportation Review, 86, 116-128. https://doi.org/10.1016/j.tre.2015.12.006

\section{General rights}

Copyright and moral rights for the publications made accessible in the public portal are retained by the authors and/or other copyright owners and it is a condition of accessing publications that users recognise and abide by the legal requirements associated with these rights.

- Users may download and print one copy of any publication from the public portal for the purpose of private study or research.

- You may not further distribute the material or use it for any profit-making activity or commercial gain

- You may freely distribute the URL identifying the publication in the public portal 


\title{
The Liner Shipping Berth Scheduling Problem with Transit Time
}

\author{
Line Blander Reinhardta ${ }^{\mathrm{a}, *}$, Christian E. M. Plum ${ }^{\mathrm{b}}$, Guillaume Vial ${ }^{\mathrm{a}}$, Mikkel M. Sigurd ${ }^{\mathrm{b}}$, David Pisinger ${ }^{\mathrm{a}}$ \\ ${ }^{a}$ DTU Management Engineering, Technical University of Denmark, Produktionstorvet 424, 2800 Kgs. Lyngby, Denmark \\ ${ }^{b}$ Maersk Line, Esplanaden 50, 1098 København K., Denmark
}

\begin{abstract}
Container shipping companies are currently facing combined challenges of overcapacity and volatile fuel prices. In addition, rising concerns about greenhouse gas emissions has made it crucial for shipping companies to reduce their fuel consumption. The consumption of fuel for shipping vessel is polynomially proportional to the speed. This study proposes a new model which for a fixed liner shipping network, minimizes the fuel consumption by adjusting the port berth times to allow for a more even speed throughout the service and thus a lower overall fuel consumption. This speed optimization is done while ensuring that given transit time limits for the carried cargo is satisfied, and considering the layover time for containers transhipping between services. The model gives the global optimal solution for an entire network of container liner services. A model which can efficiently solve real-life problems using exact methods is presented and tests on a real size liner shipping network is shown. The work has been carried out in collaboration with Maersk Line and the test instances have been verified to be representative of real-life networks.
\end{abstract}

\section{Introduction}

In the beginning of 2008, the future of maritime transportation looked remarkably bright. Major actors of the sector responded to an ever-increasing demand by increasing the fleet capacity. At the end of 2008 orders for new ships were equivalent to almost $80 \%$ of the current fleet capacity [3]. However when the economic crisis hit the liner shipping sector in 2009, a severe downturn in trade left the sector in overcapacity. As a direct consequence, freight rates dropped $28 \%$ on average [1]. As a response shipping companies deployed less capacity on their networks and by the end of $2009,12 \%$ of the global container fleet was laid up, compared to $3 \%$ at the end of 2008 [1].

Another response to the over capacity was slow steaming [8]. The slow steaming strategy has been employed by most container lines starting since 2009. While reducing bunker consumption, slow steaming may also extend the round-trip time of a service. Since liner-shipping companies generally provide weekly shipping services, the number of ships deployed on a service would then increase with the length of the round-trip time. Because of this, more vessels are needed to operate the same tour and slow steaming can absorb some of the excess carrying capacity. This makes slow steaming the most relevant option to choose in order to reduce cost and absorb vessel capacity. However the companies must still deliver attractive service times for the customers.

The Maersk bunker consumption reduction shown in Figure 1 meant lower costs for the company, (see [2]). According to Stopford [19], the bunker cost is $35 \%$ to $50 \%$ of a vessels cost and according to [2] around $21 \%$ of the company expenses. Hence, bunker consumption is a critical item for achieving cost reduction. The 2013 maritime report of the United Nations [3] goes further by linking consumption cost and environmental concerns. As a result a

*Corresponding Author, Tel.: +45 41403559 


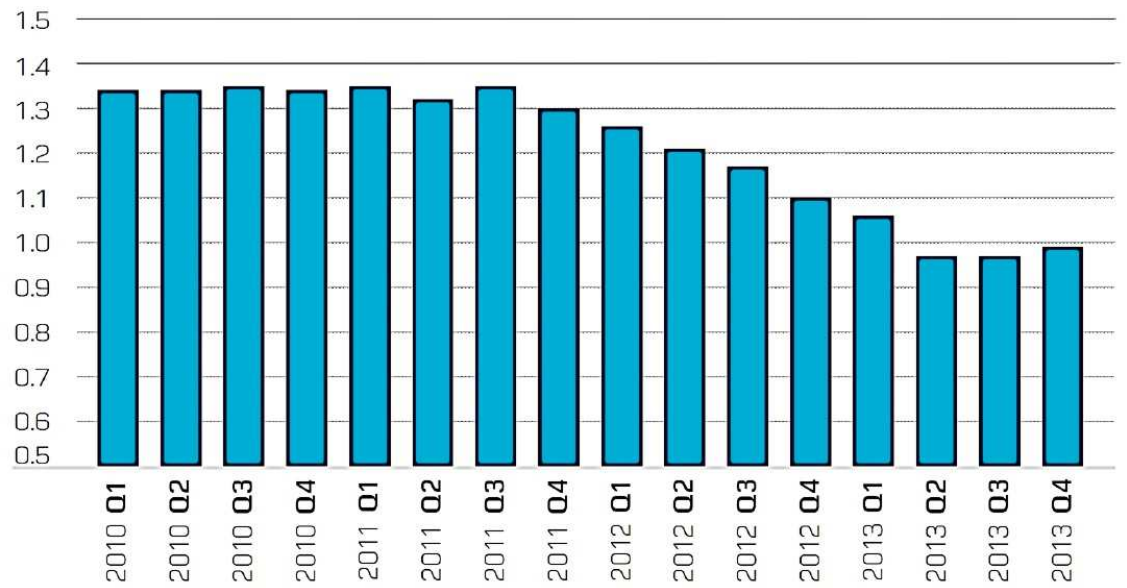

Figure 1: Development at Maersk of bunker Consumption efficiency in ton per FFE from Maersk annual report 2013 [2].

better handling of fuel consumption may reduce environmental impact and cost. With increasing oil prices this share obviously increases.

The remaining of this paper is structured as follows: In the rest of this section the slow steaming problem tackled in this paper is described. This is followed by a literature review in Section 2 The review focuses on research sharing specificities with the problem studied here. In Section 3 the constraints and variables of the problem are described together with by a detailed description on the methodology used to handle the non-linearity of the problem followed by the entire compact model in Section 4. In Section 5 the different test instances are described which is followed by computational results in Section 6. Finally, in Section 7 there is a discussion on the discoveries presented and the possible ways to improve on the results.

\subsection{The Liner Shipping Berth Schedule with Transit Time Problem}

The slow steaming strategy exploits the relation between speed and bunker consumption. However lowering the speed will obviously also result in longer transit times. Freight rate and transit time are important criteria used by customers when they choose a carrier. Brouer et al. in [6] lists nine parameters for the services that liner shipping companies can offer but also mention that only freight rate and transit time are regarded as key factors. Consequently, the negative impact of slow steaming on the transit time could cause loss of customers. Therefore, lowering speed is a tradeoff between bunker consumption and transit time.

The networks of most liner-shipping companies are organized around services that continuously serve a set of ports in a predefined sequence. A set of homogenous vessels are deployed on the service to provide a periodic service, usually weekly service. A service is made of a port sequence, a timetable, a number of ships deployed and a frequency. On the example shown in Figure 2, port sequences of three typical services are depicted. Note that the number of vessels and frequency are not depicted in Figure 2.

The implementation of slow steaming can be done at two different stages of the network design process. The implementation can happen when the service is designed and then it will influence the number of vessels deployed or the port sequence. The implementation of slow steaming can also occur when the service is already defined. At that time, only the schedule is revised in order to be re-optimized, with the goal of sailing slower on the fastest leg, and faster on the slowest. 


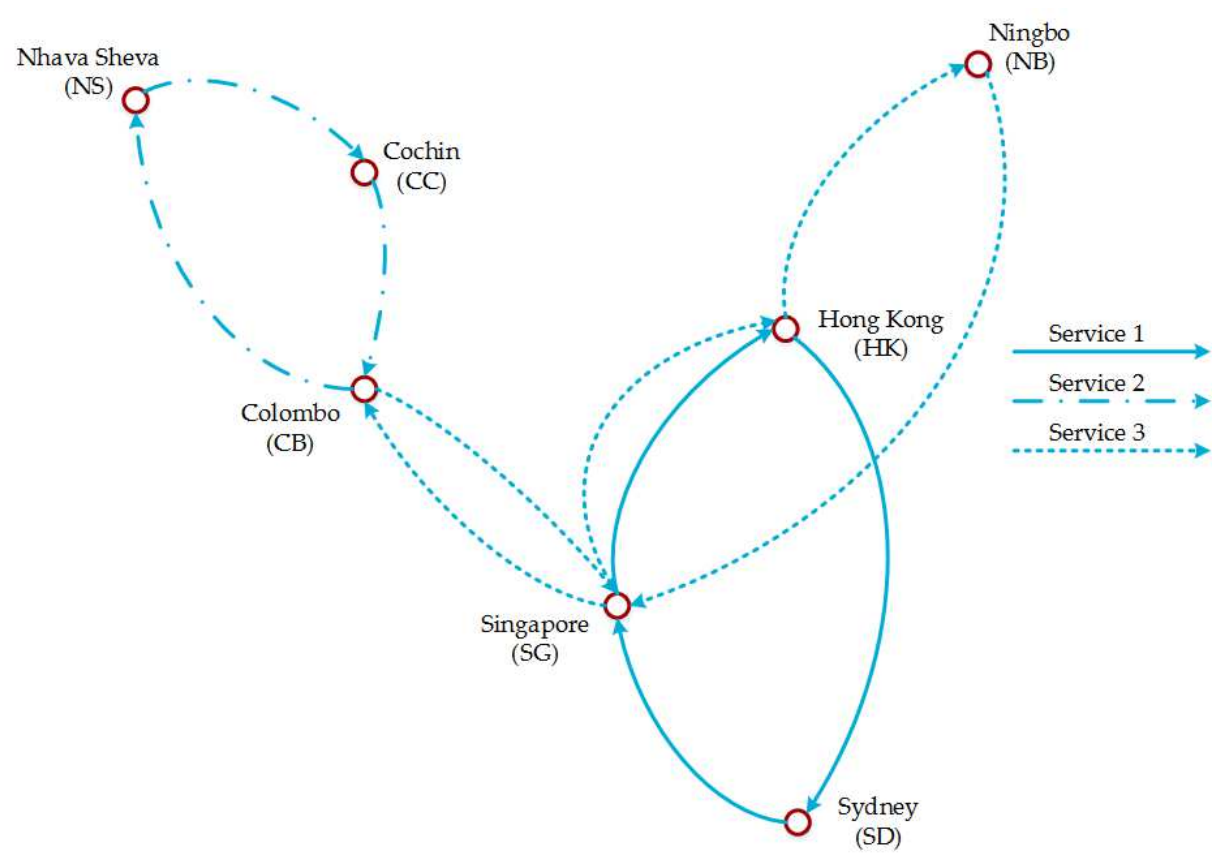

Figure 2: An example of a network containing three services with possible transhipment locations at Hong Kong, Singapore and Colombo.

Both ways have their advantages and drawbacks. The first method implies solving an integrated problem. This may prove too complex to be solved by current techniques and implementing the solution may prove impossible for strategic reasons. The second method consists of optimizing subproblems individually and is easier for a company to implement in their current network without restructuring everything and thereby avoiding the complications such a restructuring involves.

In the problem studied here only the the arrival times in the serviced ports are rescheduled.Earlier we defined a service as a port sequence, a timetable, a number of ships deployed and a frequency, in the problem studied here the port sequence, number of ships deployed and the frequency will remain the same and only the timetable is changed. The arrival times compose the schedule for each service of the network and they are limited by the sailing speed. This is why these arrival times are the decisions variables of The Liner Shipping Berth Schedule with Transit Time Problem. The slower a vessel sails the lower the bunker consumption is and therefore the arrival time has to be as late as possible in order to minimize the sailing speed and the consumption. The fleet size and the vessel mix, the round-trip time of services, the port sequence of services and the frequency of a service are are all fixed so that the only change needed to be implemented is the change of time for the port call. Under these conditions, only one vessel class is sailing each service.

With the number of vessels fixed and a frequency of one week the round trip time is fixed. A one week frequency is the standard for liner shipping operations and ports services are booked for a weekly visit. The number of days for a round trip is the number of weeks corresponding to the number of vessels. In this configuration, ensuring that the round-trip time is respected becomes a constraint in the The Liner Shipping Berth Schedule with Transit Time Problem.

Clearly, to be able to calculate transit times the time must be calculated using the same measure for all services. 
This means that the time zero must be fixed and the same for all services. Since all services has a weekly frequency time zero must be a weekday and time such as Sunday midnight (24:00) The first port call on the service is defined as the starting port. The time zero must be passed after the last port visit and either on or before the first port visit. However, since the operation of services is cyclic and periodic, the scheduling problem can redefine the temporal starting port of the service. Such a modification will result in a different schedule for the service without affecting its structure and could thus result in a redundant solution. Locating the temporal start of a service becomes another variable of the problem. Not being able to move the temporal start would put undesired restrictions on the movements of berthing times for the port calls within the first and last week of a service as the last port visit would not be able to be delayed beyond time zero and the start port visit could not be scheduled earlier than time zero.

Liner-shipping offer the transportation of customer cargo from a port of origin $O$ to a port of destination $D$. A path linking $O$ and $D$ is called a routing. Linking two ports can be done by a direct routing where the vessel leaving port $O$ is the same as the one reaching port $D$. It can also be done by using transhipment routing where the vessel carrying the cargo needs to stop along the way to tranship the cargo to another vessel that will tranship it again, if needed, until the cargo is delivered at its destination $D$. Achieving a transhipment routing can easily require several of these transhipment operations. A liner shipping network is working through transhipment to achieve many connections and ensure good capacity usage.

There may exists several different routings for a single demand (from its origin to its destination), as one routing may not have enough capacity for all the cargo. Finding the cheapest and/or fastest routings satisfying the vessel capacities is a variant of the multi commodity flow problem. In the case of The Liner Shipping Berth Schedule with Transit Time Problem, the routing problem has already been solved beforehand. With the cargo routing already defined, each of the routes are already selected and now the difficulty is to track the time it takes for a cargo to reach its destination. The time needed to travel a route is the transit time. As mentioned earlier the customers are mainly interested in the price and the duration of the transport. The transit time includes both the time spent on a vessel and time spent waiting at a port for a vessel during a transhipment. This waiting time is here referred to as the transhipment time. The transit time is a fixed parameter per connection and is important for staying competitive on the market, hence, respecting it, is a constraint of The Liner Shipping Berth Schedule with Transit Time Problem.

Figure 2 represents an example of three services with the possibility of transhipment operations at Singapore and Hong Kong between service 1 and service 2 and at Colombo between service 2 and service 3 . To achieve a transhipment operation a specific timeline needs to be followed. Figure 3 displays an example of a transhipment routing from Ningbo to Sydney with a transhipment operation in Singapore. Each week, on a fixed day and hour, a vessel from service 3 arrives in Singapore. Cargo that has to be delivered or transhipped in Singapore is discharged and some other cargo might be loaded onto the vessel. Containers that must be transhipped to service 1 are then waiting in Singapore for a vessel from service 1. To ensure a robust scheduling of transhipment operations, the waiting time usually has to be at least eight hours. This time period is called the Connecting Time Window or CTW and is usually measured from the departure of the first service to the arrival of the second service. The CTW can vary and is dependant on the services connecting in a specific port. The CTW ensures that there is enough time for the container to be transported from the unload location to the loading location of the next vessel. If the vessel from service 1 arrives immediately after the vessel of service 3, and the waiting time is less than eight hours, then transhipment does not occur. Instead, the container will wait for the next appearance of the vessel from service 3 which will take place one week later. In some specific cases, the transhipment is happening while both vessels are at berth at the same time (thus having a negative CTW). In this situation, a crane is unloading a container directly from one vessel then the container is moved by truck to another crane that loads it on the other vessel. This configuration, known as hot berthing, does not require the eight hours buffer time. Yet it does require that the berth location of the vessels are close. The positioning of the berth locations is not considered in the model however the model can work with any CTW and one can if necessary keep some of the berthing times fixed to ensure a specific hot berthing takes place as the berths in such cases can be hard to reschedule. 

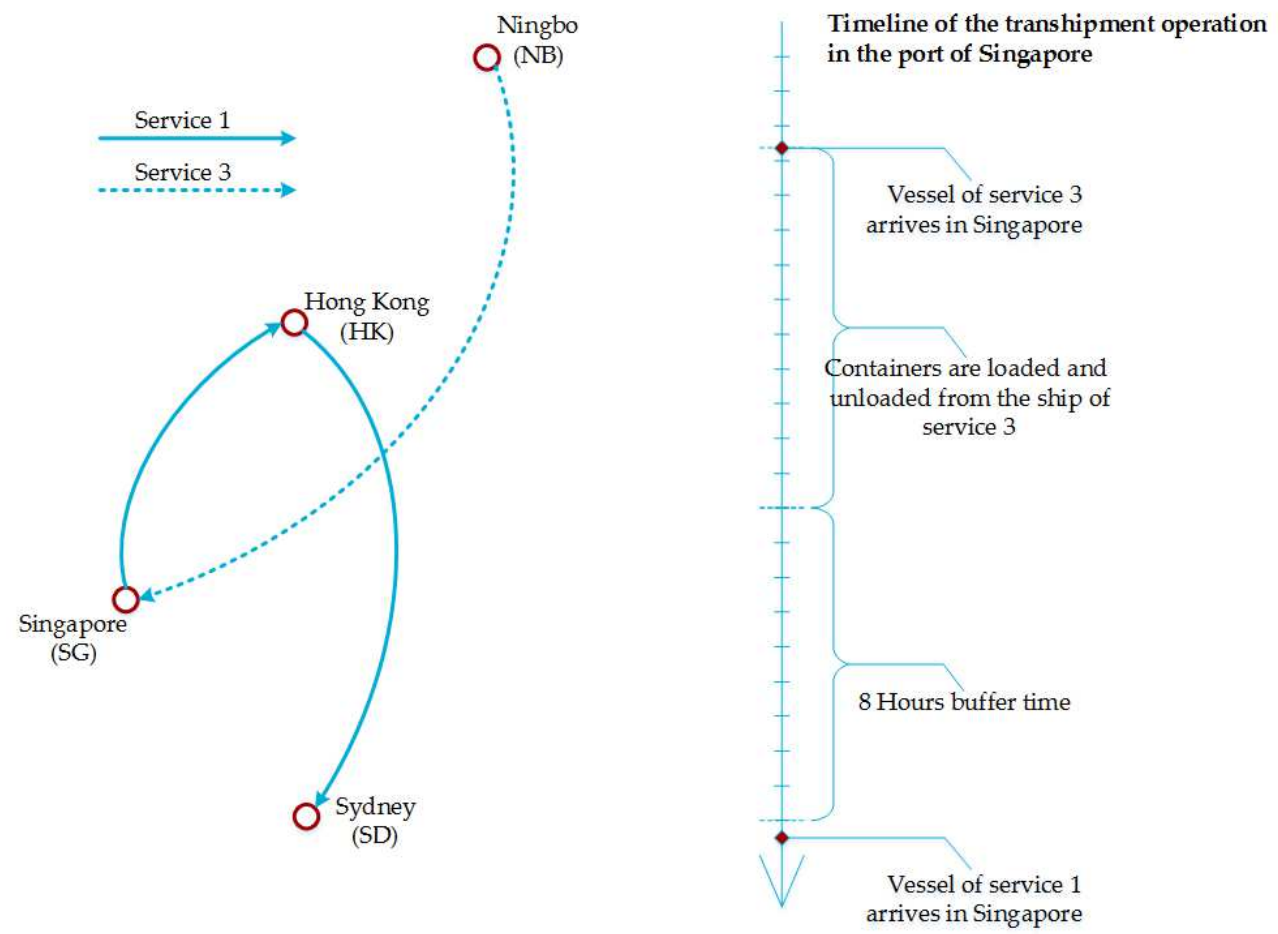

Figure 3: An example of a routing from Ningbo to Sydney on the network from Figure 2. The routing shown contains a transshipment operation in Singapore which is described to the right.

As mentioned earlier, every problem affecting the structure of the network outside of the rescheduling the port calls, is already solved prior to this problem. It implies that the fleet size and the vessel mix, the round-trip time of services, the port sequence of services and the frequency of a service are locked parameters for The Liner Shipping Berth Schedule with Transit Time Problem (called hereafter BTRSP). These conditions include that only one type of vessels are sailing on a given service.

To summarize the problem presented and solved here is introducing slow steaming by rescheduling port calls on an existing network. The benefits are that the implementation of this is straight forward for the liner shipping company. As is shown in the results reductions achieved by rescheduling port calls are significant. We present a mixed integer model which can solve many different real-life instances within seconds and show significant reductions on the fuel consumption.

\section{Literature review}

The liner-shipping area, unlike truck transportation, airline transportation and train transportation, was until the new millennium scarcely studied in operations research $[9]$. 
In [9], [10], [1] , [18] and [23] literature linked to maritime optimization problems and liner network design is reviewed. Brouer et al. [6] presented in 2014 a benchmark suite to help the research development and which also provides a good overview of the concepts of liner shipping and how the liner shipping network is structured.

Bunker cost accounts for a large share of the total liner-shipping cost: 35-50\% ([15], [18] and [19]) hence, reducing bunker consumption can result in a considerable reduction in the cost. Plum et al. in [16] give an introduction to optimization techniques for modelling bunker purchasing and how this can assist in lowering bunker cost for a liner service.

Stopford [19] explains that solving scheduling problems can bring what is called economics of speed through the decrease of bunker consumption. Cariou in [8] assesses the environmental impact of slow steaming and conclude that it is also a mean to reduce the carbon footprint of the liner shipping companies. This is adding an environmental incentive on top of the economic incentive. This means that the companies can decrease their cost and at the same time reduce their carbon emission resulting in a win-win situation.

When proceeding to slow steaming optimization, it is important to know how the consumption grows as a function of speed. There has been different suggestions for how to calculate consumption from the speed. Brown et al. [7] in 1987 suggested the super linear function based on generated schedules, Notteboom [15] in 2009 suggested an empirical consumption function extrapolated from published data. Nevertheless, engine theory and empirical data are most commonly linking sailing speed and bunker consumption through a cubic function approximation (Alderton [5] and

\begin{tabular}{|c|c|c|c|c|c|c|c|}
\hline Reference & Transhipment & $\begin{array}{l}\text { Considers } \\
\text { Round trip }\end{array}$ & Transit time & $\begin{array}{l}\text { Consumption } \\
\text { function }\end{array}$ & $\begin{array}{l}\text { Problem } \\
\text { type }\end{array}$ & $\begin{array}{l}\text { Solution } \\
\text { method }\end{array}$ & $\begin{array}{l}\text { Instance } \\
\text { size }\end{array}$ \\
\hline $\begin{array}{l}\text { Brown et al. } \\
1987[7]\end{array}$ & no & no & no & $\begin{array}{l}\text { super linear } \\
\text { function }\end{array}$ & $\begin{array}{l}\text { Tramp } \\
\text { shipping }\end{array}$ & $\begin{array}{l}\text { Column } \\
\text { generation }\end{array}$ & $\begin{array}{c}\text { Small.: } 12 \text { ports, } \\
24 \text { vessels and } 50 \text { cargos }\end{array}$ \\
\hline $\begin{array}{l}\text { Fagerholt et al. } \\
2010[12]\end{array}$ & no & $\begin{array}{l}\text { time } \\
\text { windows }\end{array}$ & no & $\begin{array}{l}\text { Quadratic } \\
\text { function }\end{array}$ & $\begin{array}{l}\text { Tramp } \\
\text { shipping }\end{array}$ & $\begin{array}{l}\text { Shortest path } \\
\text { problem }\end{array}$ & $\begin{array}{l}\text { Small: } 16 \text { ports, } \\
1 \text { vessel no cargo }\end{array}$ \\
\hline $\begin{array}{l}\text { Norstad et al. } \\
\quad 2011 \text { [14] }\end{array}$ & no & $\begin{array}{l}\text { time } \\
\text { windows }\end{array}$ & no & $\begin{array}{l}\text { Quadratic } \\
\text { function }\end{array}$ & $\begin{array}{l}\text { Tramp } \\
\text { shipping }\end{array}$ & $\begin{array}{l}\text { Heuristic } \\
\text { method }\end{array}$ & $\begin{array}{l}\text { Medium: } 40 \text { ports, } \\
13 \text { vessels, } 70 \text { cargos }\end{array}$ \\
\hline $\begin{array}{l}\text { Meng and Wang } \\
2011[13]\end{array}$ & no & yes & yes & $\begin{array}{l}\text { Cubic } \\
\text { function }\end{array}$ & $\begin{array}{c}\text { Only } \\
\text { long haul }\end{array}$ & $\begin{array}{c}\text { Outer } \\
\text { approximation } \\
\text { for non linearity }\end{array}$ & $\begin{array}{l}\text { Small: } 12 \text { ports, } \\
1 \text { service, } 1 \text { vessel }\end{array}$ \\
\hline $\begin{array}{l}\text { Reinhardt and Pisinger } \\
2011[17]\end{array}$ & no & yes & no & $\begin{array}{l}\text { Fixed } \\
\text { Speed }\end{array}$ & $\begin{array}{l}\text { Network } \\
\text { Design }\end{array}$ & $\begin{array}{l}\text { Cutting } \\
\text { Plane }\end{array}$ & $\begin{array}{l}\text { Small: } 15 \text { ports, } \\
3 \text { vessels }\end{array}$ \\
\hline $\begin{array}{l}\text { Wang and Meng } \\
2012[21]\end{array}$ & yes & $\begin{array}{l}\text { fixed } \\
\text { start time }\end{array}$ & yes & $\begin{array}{l}\text { cubic } \\
\text { function }\end{array}$ & $\begin{array}{l}\text { Probabilistic } \\
\text { version with } \\
\text { speed and flow }\end{array}$ & $\begin{array}{l}\text { Cutting plane } \\
\text { based method } \\
\text { piecewise linear }\end{array}$ & $\begin{array}{c}\text { Medium: } 46 \text { ports, } \\
11 \text { services, } \\
3 \text { vessel class, }\end{array}$ \\
\hline $\begin{array}{l}\text { Wang et al. } \\
2013 \text { [22] }\end{array}$ & no & yes & yes & $\begin{array}{c}\text { Unique } \\
\text { law per leg }\end{array}$ & $\begin{array}{l}\text { Speed, routing, } \\
\text { fleet deployment }\end{array}$ & $\begin{array}{l}\text { Several } \\
\text { methods }\end{array}$ & $\begin{array}{l}\text { Small: } 7 \text { ports, } \\
1 \text { service, } 1 \text { ship }\end{array}$ \\
\hline $\begin{array}{l}\text { Karsten et al. } \\
\quad 2013[22]\end{array}$ & yes & yes & yes & $\begin{array}{c}\text { not } \\
\text { included }\end{array}$ & flow & $\begin{array}{l}\text { Column } \\
\text { generation }\end{array}$ & $\begin{array}{l}\text { Large: } 111 \text { ports } \\
4000 \text { demands }\end{array}$ \\
\hline This paper & yes & yes & yes & $\begin{array}{l}\text { Cubic } \\
\text { function }\end{array}$ & $\begin{array}{l}\text { Speed, } \\
\text { Rescheduling } \\
\text { penalized }\end{array}$ & $\begin{array}{l}\text { branch and bound } \\
\text { Linearization of } \\
\text { cubic function }\end{array}$ & $\begin{array}{c}\text { Large: } 226 \text { ports, } \\
697 \text { vessels, } 86 \text { services, } \\
7000+\text { demands }\end{array}$ \\
\hline
\end{tabular}


Stopford [19]). In an empirical study from 2012 Wang and Meng [20] confirm that the cubic function is a good approximation for the conversion from the speed to the consumption. Clearly the cubic function is nonlinear which can complicate linear models and therefore speed optimization is often not considered when optimizing networks $([4]$, [6] and [17]).

In the table 2 we present literature in maritime shipping which considers the bunker consumption in their cost optimization. First column of Table 2 lists in chronological order articles considering bunker consumption in the modeling. The transhipment column states whether transhipment operations are allowed. The round trip column indicates if limits on the total round trip time of services is considered in the model. The transit time column shows whether there is a time restriction on the journey of the container from origin to destination. In the fifth column the consumption law used is provided. The sixth column try to give an indication of the problem solved. All the models considered except for [21] and this paper does not consider the time waiting at port during a transhipment.

From, Table 2, it can be observed that most of the solution methods have only been tried on small or medium instances. This implies that none of the cited works had to face large-scale problems, as the ones world leading liner shipping companies have to deal with.

Wang and Meng in 21] formulate a time scheduling problem using a probabilistic interpretation of the arrival time, which result in a probabilistic version of the model. In [21] it is not possible to change the temporal starting point for the services and it introduces its piecewise linear function by applying a cutting plane algorithm to solve a medium sized instance with 100 demands. Keeping a fixed temporal starting point restricts the possibilities for changing the time for the port visit during the first and last week and therefore the model may not always provide the minimal solution in cases where there is less than a week of travel time between the last and the first port.

In this paper we present a new model which includes this variable starting point for the service and with a different objective which penalizes every time a port visit is changed. The problem is solved for very large instances by using the fact that the cubic function is convex and therefore we can represent it by a series of linear constraints. However we do not optimize the flow of the cargo as in [21]. In real life finding the optimal flow on a network is complicated due to various rules such as cabotage, sanctions and others. The companies generate an optimal default flow set on a network when the network is altered. Changes in routing of demands are often only carried out for a few demands as the changes may create implementation chaos in the operation with containers ending up on the wrong vessels. Thus we use the routes already implemented. The solution found by our algorithm is as a result easier for the company to implement as it only involves changing port visit times.

By using an network resembling a real-life network we can get a somewhat realistic estimate for amount of reduction of bunker consumption which can be achieved by a company by simply changing the time of the port calls. As we shall see later the number of routes with constrained transit times and containing transhipment is what increases the complexity of the problem.

\section{Mathematical Problem formulation and model}

In this section the BTRSP is explained in more details. Let $R$ be the set of all services, each service has a duration which is divisible by a number of weeks. Let $w_{r}$ be the number of weeks representing the duration of a service $r \in R$. Let $L_{r}$ be the ordered set of legs on service $r \in R$ where $n_{r} \in L_{r}$ is the last leg in the list of a service $r \in R$ and where the legs are ordered by the port visit sequence. Then, let $t_{l_{r}}$ be a continuous nonnegative variable containing the departure time from the end port of leg $l$ on service $r$. The domain for $t_{l_{r}}$ is $\left[0,168 w_{r}\right]$ where 168 is the number of hours in a week. It is possible to reduce the domain using the order of the legs on the rotation and the minimum time needed on each of them. 


\subsection{Objective minimizing bunker cost}

The overall aim of the model is to minimize the bunker consumption using penalties to limit number of changes in the port visit time. Since it is assumed that the company already has a working schedule there exists port visits times and leaving a port at this original port visit time will not involve any work or cost. However, changing the port visit time is costly and we will therefore not change it unless the savings are somewhat significant. Therefore we introduce a penalty for changing the port visit time.

\subsection{Scheduling port visits}

To ensure that all vessels and services are using the same clock a global time is used (Greenwich Mean Time) and time zero is defined as Sunday at 24:00. A service is cyclic as seen in Figure 2 A first port visit on the service with departure time scheduled for Monday at 12:00 cannot be the first leg if rescheduled for Sunday 12:00, given the common time zero at Sunday 24:00, the previous port visit on the service occurs with in the same week. Therefore the problem contains a variable $F_{l_{r}}$ which is 1 if leg $l_{r}$ ends at the first port visit time of service $r$. Clearly there is exactly one first port visit on a service. Ensuring that exactly one start leg is selected is modeled by the following constraint:

$$
\sum_{l_{r} \in L_{r}} F_{l_{r}}=1, \forall r \in R
$$

Then the time used on a leg $l_{r}$ is the time the vessel departs from the end port $t_{l_{r}}$ of leg $l_{r}$ minus the time the vessel depart from the end port on the previous leg $t_{l_{r}-1}$. When $r=0$ then we let $r-1=n_{r}$. When $l_{r}$ is the first leg on the service we must add the service time $168 \cdot w_{r}$ to get the time on leg $l_{r}$.

\subsubsection{Portstay and pilottime}

In the time between $t_{l_{r}-1}$ and $t_{l_{r}}$ there are several segments.

Port stay This is the time the vessel spends at berth in the port to unload and load containers, load bunker and others. For a leg $l_{r}$ the portstay at the end port is included in the overall time $t_{l_{r}}$. The portstay at the destination port of leg $l_{r}$ is denoted as $d s_{l_{r}}$

Pilot out This is the pilot time used on leaving the start port of the leg.

Pilot in This is the pilot time used on entering the end port of the leg.

Let the time on a leg used on piloting (both out and in) be denoted $p t_{l_{r}}$. On the distance sailed while piloting a fixed speed is used and therefore this distance can not be speed optimized. The pilot in and pilot out of a port thus has influence on the distance and time on which the speed is based $d_{l_{r}}$. Therefore the distance and time must be subtracted the real distance and time of the leg. For very close ports there may not be any distance sailed without using a pilot thus, leaving the leg with no room for speed optimization. For a graphic illustration of this see Figure 4

Then it is possible to represent the time $\tau_{l_{r}}$ which defines the speed on the distance $d_{l_{r}}$ as :

$$
\tau_{l_{r}}=t_{l_{r}}-t_{l_{r}-1}-d s_{l_{r}}-p t_{l_{r}}, \quad \forall l_{r} \in L_{r}
$$

Note that by definition $\tau_{l_{r}}$ will always be positive. In fact $\tau_{l_{r}}$ will be greater than or equal to the time it takes to sail the distance $d_{l_{r}}$ at maximum speed. 

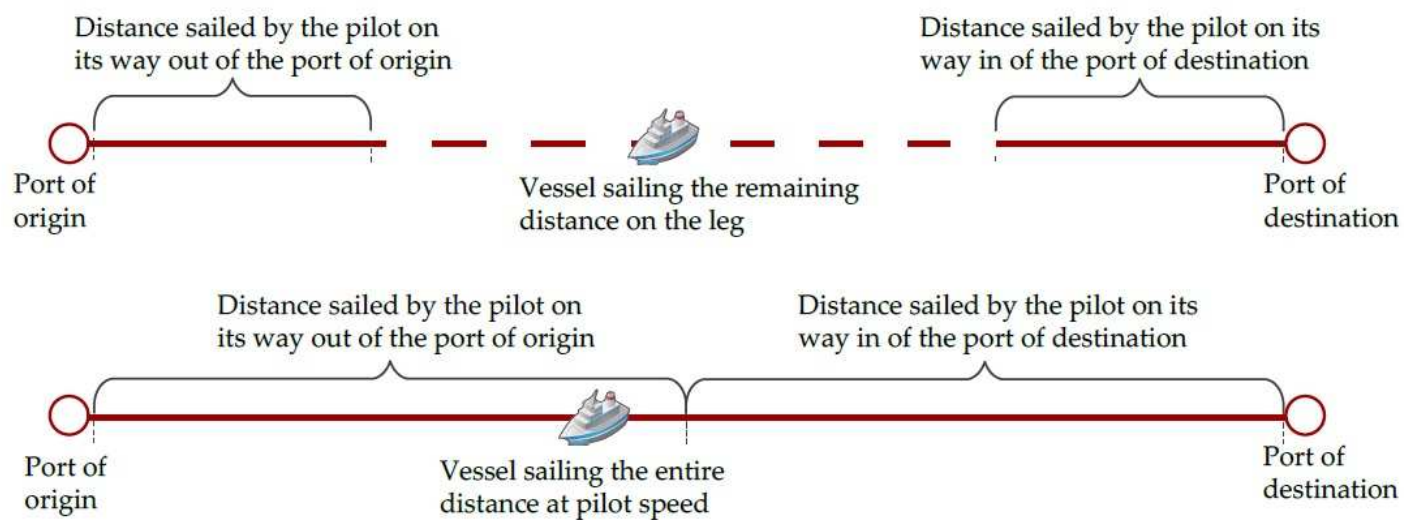

Figure 4: A graphic representation of the different parts of a leg. The top diagram shows the case where there is some distance on the leg that is not part of the piloting. The diagram below shows the case where the leg distance is equal to the out and in piloting required on the leg.

\subsection{Maximum and minimum sailing speed}

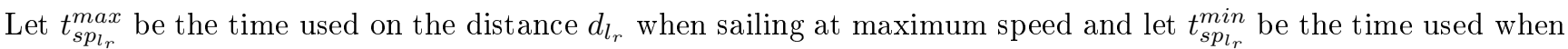
sailing the distance at the minimum sailing speed. Clearly a vessel has a maximum speed at which it cannot sail faster, $\tau_{l_{r}} \geq t_{s p_{l_{l}}}^{\max }$, meaning that the time spent on sailing the distance must be greater than or equal to the time needed to sail the distance at maximum speed.

The vessels also has a minimum speed which is required to be able to maneuver the vessel. This minimum speed is only used for calculating the bunker consumption. The minimum speed does not restrict the time spend on the leg which can be much larger allowing for the ship to lay waiting for their berth time outside a port.

Let $C B\left(\tau_{l}\right)$ be the cost of the bunker used for sailing the leg $l$ in time $\tau_{l_{r}}$. Then we have the constraint that $C B\left(\tau_{l_{r}}\right) \geq C B\left(\right.$ tminsp $\left._{l_{r}}\right)$. In other words the minimum speed will provide a lower bound for the amount of bunker required for sailing a leg. The minimum speed of a vessel is provided as the pilot speed which is used for sailing in and out of ports. The different ports have different distances for which a pilot must be on board for navigation and the vessel must sail slowly. The distances depend on how accessible the port is from the sea.

\subsection{Bunker consumption}

For the bunker consumption we use the cubic function presented in [6]:

$$
B(\delta)=\left(\frac{\delta}{\delta_{v}}\right)^{3} B\left(\delta_{v}\right)
$$

Where $\delta$ is the speed used and $\delta_{v}$ is the design speed of vessel class $v . B\left(\delta_{v}\right)$ is the bunker consumption at the design speed and $B(\delta)$ is the bunker consumption at speed $\delta$. The design speed $\delta_{v}$ and the bunker consumption at design speed $B\left(\delta_{v}\right)$ are part of the specifications of a vessel and therefore known for each vessel and engine. 


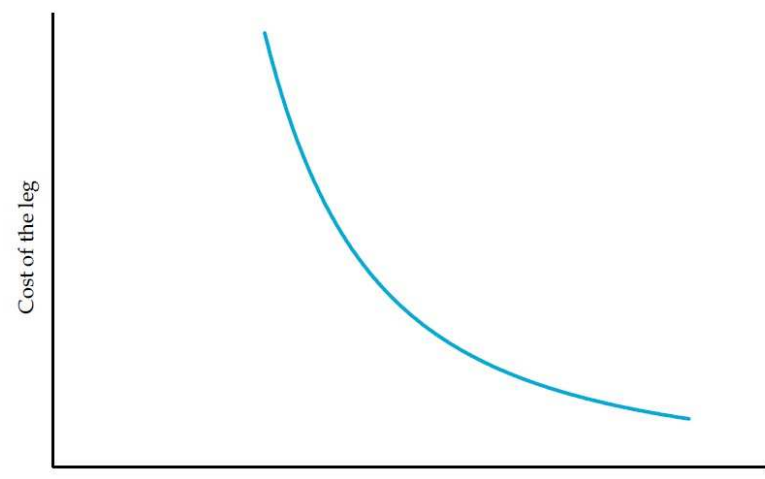

Time spent sailing on the leg

(a)

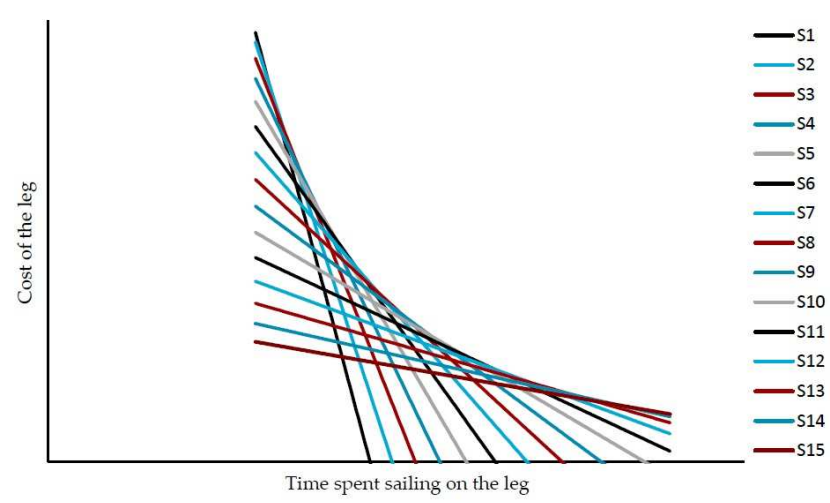

(b)

Figure 5: Figure (a) shows the bunker consumption on a leg as a function of time used on sailing the leg. Figure (b) The bunker consumption on a leg approximated by 15 secants.

Here we will apply the bunker price calculated using the duration of the leg and the given length of the leg to calculate the consumption. The time used when sailing the leg $l_{r}$ at design speed of vessel type $v$ is denoted as $\tau_{v}$. Thus the speed can be represented as $\delta_{l_{r}}=\frac{d_{l_{r}}}{\tau_{l_{r}}}$ and $\delta_{v}\left(l_{r}\right)=\frac{d_{l_{r}}}{\tau_{v}}$ where $\delta_{l_{r}}$ is the speed used on leg $l_{r}$. By using the conversion from speed to time, equation (3) can be reformulated as:

$$
C B\left(\tau_{l_{r}}\right)=\left(\frac{\tau_{v}}{\tau_{l_{r}}}\right)^{3} B\left(\delta_{v}\right) \tau_{l_{r}} C B_{u}
$$

Where $C B_{u}$ is the price per metric tonne of bunker and $C B\left(\tau_{l_{r}}\right)$ is the price for bunker consumed when using time $\tau_{l_{r}}$ to sail leg $l_{r}$. This equation finds the bunker cost of a leg $l_{R}$. The function in equation (4) can be seen in Figure 5 (a).

To circumvent the nonlinearity of this function we have chosen to make a piecewise linear representation. Since the bunker cost function is convex we can construct the linear representation by using a set of linear constraints. We have chosen to do this by a set of linear constraints representing secants to the function. These secants are evenly distributed along the curve. The number of secants used in the approximation is provided as input.

Let $P$ be the set of secants used to approximate the bunker cost. The linear functions of the secants must be generated for each leg to account for the varying distance. For each secant a linear function of $C B\left(\tau_{l_{r}}\right)$ is defined as:

$$
C B\left(\tau_{l_{r}}\right)=\phi_{l_{r} p} \tau_{l_{r}}+\omega_{l_{r} p}
$$

where $\phi_{l_{r} p}$ is the slope of the secant $p \in P$ of the leg $l_{r}$ and $\omega_{l_{r} p}$ is the secants intersection with the $\mathrm{y}$ axis. Figure 5 (b) shows a set of secants approximating the bunker cost as a function of time.

\subsection{Demands and their transit time constraints}

Let $D$ be the set of demands which are to be shipped by the shipping company. Each demand $d \in D$ contains an origin, destination, amount, duration for transport and a price. The duration for the transport of the demand from origin to destination is in the remainder of this paper referred to as transit time. The company has a set of routes 


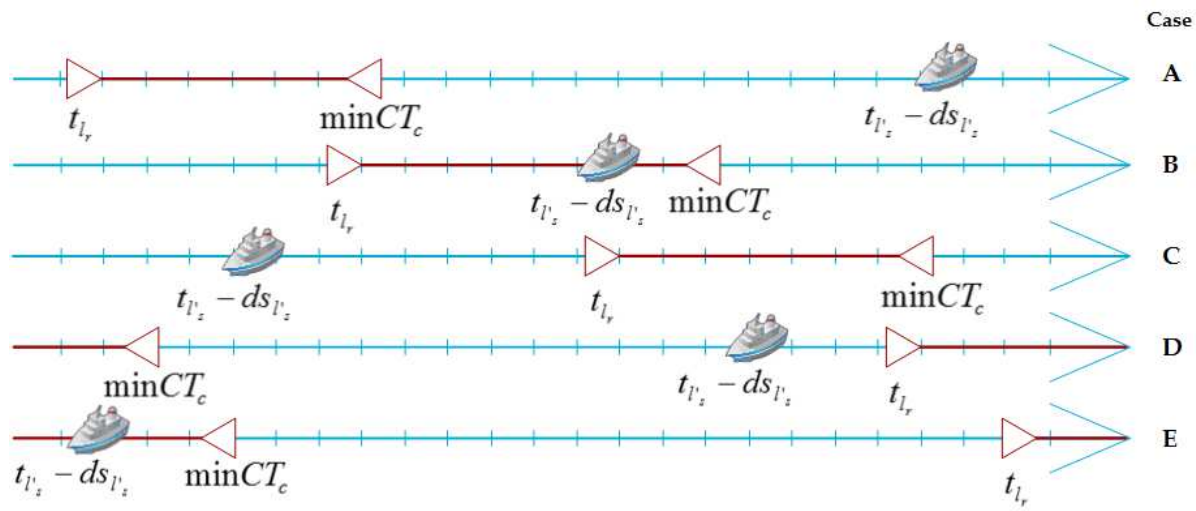

Figure 6: Five different cases for a connection $c=\left(l_{r}, l_{s}^{\prime}\right)$. In case A the leg $l_{s}^{\prime}$ arrives more than $C T_{c}^{m i n}$ after the leg $l_{r}$ departs in the same week and the time the container waits at port is $t_{l_{s}^{\prime}}-d s_{l_{s}^{\prime}}-t_{l_{r}}$. Case $\mathrm{B}$ the leg $l_{s}^{\prime}$ arrives less than $C T_{c}^{m i n}$ later in the week than the leg $l_{r}$ departs and the time the container waits at the port is $t_{l^{\prime}}-d s_{l^{\prime}}-t_{l_{r}}+168$. Case C the leg $l_{s}^{\prime}$ arrives earlier in the week than the leg $l_{r}$ departs and the container must wait at the port for $t_{l_{s}^{\prime}}-d s_{l_{s}^{\prime}}-t_{l_{r}}+168$ hours. Case D is the same as case C where the connection time goes into the next week here the time waiting at port is again $t_{l^{\prime}}-d s_{l^{\prime}}-t_{l_{r}}+168$. Case E the leg $l_{s}^{\prime}$ arrives earlier in the week than the leg $l_{r}$ departs and earlier than the connection time therefore the container must wait $t_{l_{s}^{\prime}}-d s_{l_{s}^{\prime}}-t_{l_{r}}+2 * 168$ hours at the port.

used for shipping the demand. The reason for using the existing set of demand routes is that they need to know that there is capacity for the amounts and that restrictions such as cabotage and embargoes, port visit draft and so forth are satisfied as explained in the introduction.

When rescheduling the port visits the transit time of a demand may change. It is important that the company can make sure that the transit time stays within their requirements so that customers are not lost. The transit time of a demand $d \in D$ which must be satisfied is denoted as $T T_{d}$.

The transit time can be calculated as the time the container is on the vessels, which again can be calculated from the time $t_{l_{r}}$ of the legs on the route. If the route contains transhipment the time the container must wait at a terminal for the next vessel must also be considered in the transit time.

The services have a weekly departure from each port therefore a container will not wait longer than a week plus the time required between the vessels for the container to make the connecting vessel. Thus the time of week the port visit occurs must be determined. To calculate the time of week the port visit occurs a variable $W_{l_{r}}$ is used representing the whole number of weeks.

Let $C$ be the set of connections $c=\left(l_{r}, l_{s}^{\prime}\right)$ where $l_{r}$ ends at a port $i$ and leg $l_{s}^{\prime}$ starts at port $i$ and service $r \neq s$. Let $C_{d}$ be the connections used by demand $d \in D$. Note that two different demands $d$ and $d^{\prime}$ may have connections in common. Let $C T_{c}^{\text {min }}$ be the minimum required connection time for the connection $c$.

Clearly if a demand using a connection where the arrival time of the vessel on which the container must leave, is more than $C T_{c}^{\text {min }}$ after the departure of the vessel the container arrives on then the time the container must wait at the port can be expressed as:

$$
t_{l_{s}^{\prime}}-t_{l_{r}}-d s_{l_{s}^{\prime}}-C T_{c}^{\text {min }}
$$

In a connection where the arriving leg departs later in the week than the departing leg arrives, $t_{l_{s}^{\prime}}-t_{l_{r}}-d s_{l_{s}^{\prime}}$ is negative. To find the real waiting time a week must be added, also in the case where the minimum connection time $C T_{c}^{\text {min }}$ is not satisfied the container must wait another week at the port.

The five different cases are depicted in Figure 6. Note that to get the real waiting time it may be necessary to add up to two weeks to the expression $t_{l_{s}^{\prime}}-t_{l_{r}}-d s_{l_{s}^{\prime}}-C T_{c}^{\text {min }}$. We represent the number of weeks to be added by a 
variable $x_{c}$, where $c \in C$ is the connection it represents.

Using this we formulate the connection requirements with the following constraint:

$$
t_{l_{s}^{\prime}}-t_{l_{r}}-d s_{l_{s}^{\prime}}-C T_{c}^{\text {min }}-168\left(W_{l_{s}^{\prime}}-W_{l_{r}}-x_{c}\right) \geq 0, \forall c=\left(l_{r}, l_{s}^{\prime}\right) \in C
$$

However in the case where $t_{l_{s}^{\prime}}-168 W_{l_{s}^{\prime}}-d s_{l_{s}^{\prime}}$ is negative then at least a week must be added (implying $x_{c} \geq 1$ ) to satisfy the constraint 7 . However the container may not wait at the port for a week. Therefore we introduce a binary variable $a_{l_{s}^{\prime}}$ to indicate if we have to add a week to be positive. This week is included when satisfying connection requirements but should be subtracted in the transit time calculation to ensure accurate transit times. Therefore the constraint becomes:

$$
t_{l_{s}^{\prime}}-t_{l_{r}}-d s_{l_{s}^{\prime}}-C T_{c}^{\text {min }}-168\left(W_{l_{s}^{\prime}}-W_{l_{r}}-x_{c}-a_{l_{s}^{\prime}}\right) \geq 0, \forall c=\left(l_{r}, l_{s}^{\prime}\right) \in C
$$

The constraints can now be used to formulate the transit time constraints. As mentioned earlier the transit time consists of the time spend on the legs and the time spend in the terminal during a transhipment also called the connection time.

$$
\sum_{c=\left(l_{r}, l_{s}^{\prime}\right) \in C_{d}}\left(t_{l^{\prime} s}-t_{l_{r}}-168\left(W_{l_{s}^{\prime}}-W_{l_{r}}-x_{c}+a_{l_{s}^{\prime}}\right)\right)+\sum_{l_{r} \in L_{d}}\left(t_{l_{r}}-t_{l_{r}-1}+168 w_{r} F_{l_{r}}\right)-d s_{l_{r} d} \leq T T_{d}, \quad \forall d \in D
$$

In this constraint $T T_{d}$ is the transit time limit of demand $d$ and the $d s_{l_{r} d}$ is the port stay at the destination port of demand $d$. The set $L_{d}$ contains the legs on which the cargo is sailed. These constraints are added to the model for all demands transported on legs where speed may be changes.

\section{Model}

In the previous section the different components of the model were explained. In this section we will give a complete overview of the model.

$$
\min \sum_{r \in R} \sum_{l \in L_{r}} C_{l_{r}}+\hat{P} \cdot m_{l_{r}}
$$




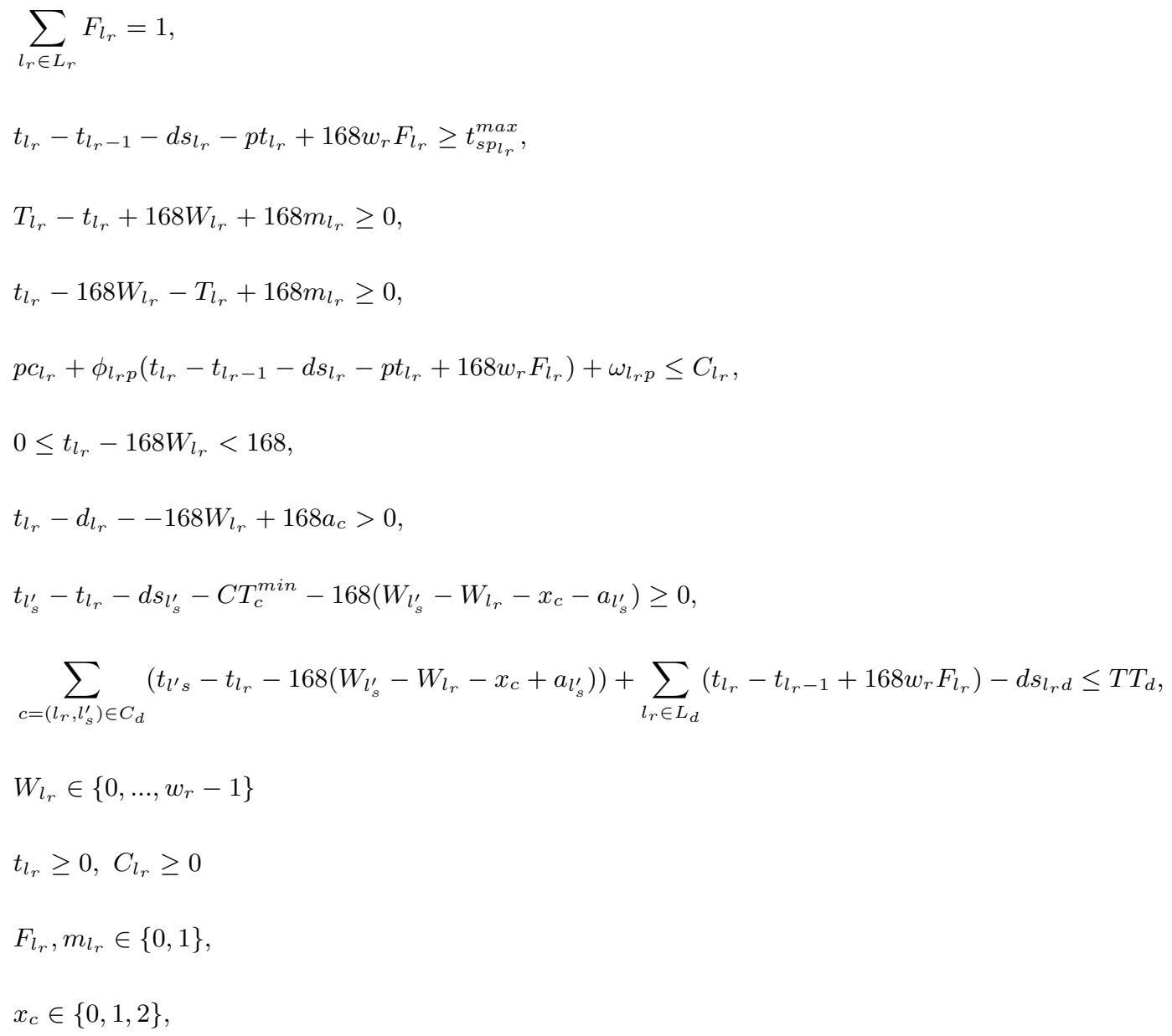

$\forall r \in R, l_{r} \in L_{r}$

$\forall r \in R, l_{r} \in L_{r}$

$\forall r \in R, l_{r} \in L_{r}$

$\forall r \in R, l_{r} \in L_{r}, p \in P$

$\forall r \in R, \forall l_{r} \in L_{r}$

$\forall l_{r} \in L_{r}$

$\forall c=\left(l_{r}, l_{s}^{\prime}\right) \in C$

$\forall d \in D$

$\forall r \in R, l_{r} \in L_{r}$

$\forall r \in R, l_{r} \in L_{r}$

$\forall r \in R, l_{r} \in L_{r}$

$\forall c\left(l_{r}, l_{s}^{\prime}\right) \in C$

The objective (10) is the bunker cost plus a penalty for every port moved. The parameter $\hat{P}$ is the penalty for moving the port time and the binary variable $m_{l_{r}}$ is one if the port call time of leg $l_{r}$ has been moved and zero if it remains the same. $C_{l_{r}}$ is the bunker cost on leg $l_{r}$.

The first constraints in the model (11) ensure that exactly one leg is chosen as the first for each service. Constraints (12) ensure that the leg is not sailed at a faster speed than the maximum speed of the vessel. The constraints (13) and (14) ensure that a penalty is applied if port time is changed from the original scheduled (weekly) port visit time $T_{l_{r}}$ of leg $l_{r}$. For every leg the consumption is restricted by a set of linear functions represented by constraints (15). In the constraints (15) the variable $\phi_{l_{r} p}$ is the slope of secant $p$ on leg $l_{r}, \omega_{l_{r} p}$ is the intersection of the secant and $p c_{l_{r}}$ is the fixed cost used on piloting on leg $l_{r}$. Note that the minimum consumption on a leg is where $\phi_{l_{r}(\min )}=0$ and $\omega_{l_{r}(\min )}$ is bunker cost for sailing the distance at the vessels minimum sailing speed. Constraints (16) find in whole weeks the time $t_{l_{r}}$. Constraints (18) ensure that the container waits at terminal for the next vessel arriving after the minimum required connection time $C T_{c}^{\text {min }}$. The transit time is ensured to be below the requirement $T T_{d}$ for demand $d$ with constraint (19). (20) to (23) define the variable domains. The variables (21) are real valued variables indicating the time of port departure and the bunker consumption cost.

In the model presented all constraints are listed, however in the implementation constraints where data has been 
fixed and limiting the domains of the variables are done in pre-processing.

\section{Test data}

For the tests cases a network containing 85 services is used. This network is constructed by taking some existing services from the major companies and combining and altering them so that a new reasonable network of the whole world is constructed. Although the network is not an existing network it has been verified and altered with our business partner and has been deemed to be a network which could be applied. The services in the generated network has a weekly frequency and port visit times are applied to all ports. These port visit times are taken from existing services which are published on the internet for the different companies and it is ensured that the services and port visit times satisfies the speed and round-time constraint. The demands are constructed with help from a liner shipping company. For the large liner shipping companies there can be up to 20,000 demands however since each demand must have at least one route on the network we have only been able to construct 7406 demands which we deem a reasonable size for testing of the model.

The same network is basis for all tests. The characteristics of the network are listed in table 1

\begin{tabular}{|c|r|}
\hline \multicolumn{2}{|c|}{ Network properties } \\
\hline Services & 85 \\
Ports & 210 \\
Legs & 1040 \\
Demands & 7406 \\
Connections & 1978 \\
Max \# routes per demand & 1 \\
Total routes & 7406 \\
Vessel types & 6 \\
\hline
\end{tabular}

Table 1: A list of the properties of the network the test instances are constructed on.

\begin{tabular}{|l|r|r|r|r|r|}
\hline Instance & Open services & Open port visits & Open demands & Open connections & Open legs \\
\hline Single service & 1 & 18 & 289 & 72 & 18 \\
Two services & 2 & 39 & 736 & 164 & 39 \\
Cluster & 12 & 25 & 1068 & 131 & 37 \\
Whole network & 85 & 1040 & 7406 & 1978 & 1040 \\
\hline
\end{tabular}

Table 2: Here is listed the different properties of the instances such as how many port visits may be changed and how many demands may be affected by changing the port visits.

Based on this network we have created a number of test instances. These test instances are created by selecting some subset of the ports called and allowing them to be rescheduled. In the instance named "Single Service" we open all port visits on a single service, which consists of 28 port visits and 289 demands uses this service as part of their journey from origin to destination. In the "Two Services" all port visits on two services are opened. The two services are different from the single service in the previous instance. The two services chosen calls some of the same ports and there exists demand which tranships between the two services. In the instance named "Cluster" we have selected a set of ports in the same region and opened visits to these ports on different services. In this case just some of the 
port visits on a number of services is opened. The open demand is demand which goes through one of these opened port visits. For the instance "Whole network" we have opened all port visits and all the services on the network can be changed.

In the test the improvements on the network depending on the transit time limit is also tested. 4 different cases are constructed: One where the current transit time is extended with 2 hours as this is very close to the original and probably will not affect the customers significantly. One with 24 hours as this is where the customers will start to notice. One with 48 hours to show the change from one day to the next and last we have a case where there is no transit time limit. We have assumed that the bunker price is $\$ 600$ per ton and have a penalty for changing a port visit time to $\$ 1000$ (per week) resulting in a penalty of $\$ 52000$ per year. The penalty for changing a port visit was provided by the liner shipping company as a desirable penalty.

\section{Results}

The cases presented in Table 2 have been run using CPLEX 12.5 on a Linux computer with a 64 bit Intel Xeon 2.67 GHz CPU. The results from the runs are shown in Table 3. The instance name is provided in the first column of Table 3. The second column shows the number of hours by which the transit times are allowed to change with respect to the current transit time. Column 3, 4, 5 and 6 show information about the result of the test. Column three shows how many ports visits times has changed. Here it is important to remember that there is a significant penalty introduced for changing the port visit time. The fourth column shows the reduction in fuel consumption achieved from optimizing. This improvement is the cost $C_{l_{r}}$ on the legs $l_{r}$ where the duration may be changed due to open port visit time also called the open legs compared to the cost of these legs on the original network. The cost of the legs on the remaining network is disregarded. The fifth column shows the running time in seconds and the last column shows the gap between the lower bound and the best found feasible solution. The cases show good reductions and the running times for the three cases containing parts of the network are quite short. However when the entire network is opened the problem is not solved within the 10 minute time limit allowed in Table 3. Another interesting observation is that a substantial saving can be obtained from 2 hours transit time slack to 24 hours slack. However increasing the slack from 24 to 48 hours does not seem to introduce much new saving. When the transit time is not considered the savings are increased significantly.

In Table 4 the entire network instance are run for one hour each. The solutions are improved and in most cases the solution from Table 3 is reduced. It is however hard for the solver to find the initial solution in the case with a slack of 48 hours which can also be seen by the lack of improvement to the solution.

\section{Conclusion}

We have presented a model which can find the optimal schedule for an existing network. The test results show that it is possible to reduce bunker consumption significantly for real-life services simply by rescheduling the port visit times. Even though the reduction is just a few percent it can for large companies still result in up to 9 digit dollars of saving per year 1 . The cases where all port visits on the entire network are allowed to be rescheduled may provide savings of that size. The interesting results from the tests is that significant savings already appear when allowing the transit time to increase with a day ( 24 hours). In a competitive environment such savings are important. We show that if only parts of the network are rescheduled the problem can be solved fast. However, if the whole network is

\footnotetext{
${ }^{1}$ In Maersk annual report 2013 [2] 8.8 million FFE's were transported and the unit cost was 2,731 US dollars. This means that the bunker cost would according to Stopford [19] be 8 billion dollars per year. Clearly even a percent of 8 billion dollars is 80 millions dollars and can therefore result in huge saving for a company.
} 


\begin{tabular}{|c|r|r|r|r|r|}
\hline Instance & Transit time extention (hours) & Ports calls changed & Cost reduction & Time (s) & Gap \\
\hline Single service & 2 & 9 & $1.97 \%$ & 1 & optimal \\
Single service & 24 & 12 & $4.71 \%$ & 2 & optimal \\
Single service & 48 & 12 & $4.71 \%$ & 1 & optimal \\
Single service & - & 14 & $7.43 \%$ & 1 & optimal \\
Two services & 2 & 13 & $0.86 \%$ & 2 & optimal \\
Two services & 24 & 23 & $2.40 \%$ & 7 & optimal \\
Two Services & 48 & 27 & $2.73 \%$ & 7 & optimal \\
Two services & - & 30 & $6.91 \%$ & 20 & optimal \\
Cluster & 2 & 16 & $1.18 \%$ & 2 & optimal \\
Cluster & 24 & 16 & $2.34 \%$ & 2 & optimal \\
Cluster & 48 & $-2.34 \%$ & 3 & optimal \\
Cluster & - & 16 & $2.48 \%$ & 2 & optimal \\
Whole network & 2 & 16 & 600 & $1.02 \%$ \\
Whole network & 24 & 450 & $1.39 \%$ & 600 & $2.36 \%$ \\
Whole network & 48 & 575 & $3.48 \%$ & 600 \\
Whole network & - & 582 & $3.66 \%$ & 600 & $3.57 \%$ \\
\hline
\end{tabular}

Table 3: Test results with the different instances for which properties are described in Table 2 The time limit is 10 minutes.

\begin{tabular}{|c|r|r|r|r|r|}
\hline Instance & added transit time (hours) & ports calls changed & cost reduction & time (s) & gap \\
\hline Whole network & 2 & 438 & $1.75 \%$ & 3600 & $0.75 \%$ \\
Whole network & 24 & 659 & $3.99 \%$ & 3600 & $1.17 \%$ \\
Whole network & 48 & 582 & $3.66 \%$ & 3600 & $3.57 \%$ \\
Whole network & - & 751 & $7.57 \%$ & 3600 & $0.29 \%$ \\
\hline
\end{tabular}

Table 4: Test results with the total network instance with a time limit of one hour.

rescheduled and limits are applied on all the transit times then the solver was not able to close the gap to the lower bound but significant reductions are still achieved. Since there are so many demands in a real-life network and each transhipment in the presented model introduces new integer variables the demands are the primary contributor to the running time. We show that the model can solve realistic problems of a reasonable size and achieve good solutions to large problems and improve the current solutions.

\section{References}

[1] Annual report. A.P. Møller - Mærsk A/S., 2009. Copenhagen, Denmark.

[2] Annual report. A.P. Møller - Mærsk A/S., 2013. Copenhagen, Denmark.

[3] Review of maritime transport. Geneva, UNCTAD - United Nations Conference on Trade and Development. Switzerland: United Nations Publications, 2013.

[4] R. Agarwal and O. Ergun. Ship scheduling and network design for cargo routing in liner shipping. Transportation Science, 42(2): 175-196, 2008.

[5] P Alderton. Reeds sea transport-operations and economics. Bloomsbury Academic, London, 2005. 
[6] B. D. Brouer, J. F. Alvarez, C. E. Plum, D. Pisinger, and M. M. Sigurd. A base integer programming model and benchmark suite for liner-shipping network design. Transportation Science, 48(2):281-312, 2014.

[7] G. G. Brown, G. W. Graves, and D. Ronen. Scheduling ocean transportation of crude oil. Management Science, 33(3):335-346, 1987.

[8] P. Cariou. Is slow steaming a sustainable means of reducing co2 emissions from container shipping? Transportation Research Part D: Transport and Environment, 16(3):260-264, 2011.

[9] M. Christiansen, K. Fagerholt, and D. Ronen. Ship routing and scheduling: status and perspectives. Transportation Science, 38(1): $1-18,2004$.

[10] M. Christiansen, D. Ronen, B. Nygreen, and K. Fagerholt. Maritime transportation. In Handbooks in Operations Research and Management Sciences, pages 189-284. North Holland, 14 edition, 2007.

[11] M. Christiansen, K. Fagerholt, B. Nygreen, and D. Ronen. Ship routing and scheduling in the new millennium. European Journal of Operational Research, 228(3):467 - 483, 2013.

[12] K. Fagerholt, G. Laporte, and I. Norstad. Reducing fuel emissions by optimizing speed on shipping routes. Journal of the Operational Research Society, 61(3):523-529, 2010.

[13] Q. Meng and S. Wang. Optimal operating strategy for a long-haul liner service route. European Journal of Operational Research, 215 (1):105-114, 2011.

[14] I. Norstad, K. Fagerholt, and G. Laporte. Tramp ship routing and scheduling with speed optimization. Transportation Research Part C: Emerging Technologies, 19(5):853-865, 2011.

[15] T. E. Notteboom and B. Vernimmen. The effect of high fuel costs on liner service configuration in container shipping. Journal of Transport Geography, 17:325-337, 2009.

[16] C. E. M. Plum, D. Pisinger, and P. N. Jensen. Bunker purchasing in liner shipping. In Chung-Yee Lee and Qiang Meng, editors, Handbook of Ocean Container Transport Logistics, volume 220 of International Series in Operations Research 8 Management Science, pages 251-278. Springer International Publishing, 2015. ISBN 978-3-319-11890-1. doi: 10.1007/978-3-319-11891-8 9.

[17] L.B. Reinhardt and D. Pisinger. A branch and cut algorithm for the container shipping network design problem. Flexible Services and Manufacturing Journal, 24(3):349-374, 2012.

[18] D. Ronen. Ship scheduling: the last decade. European Journal of Operational Research, 71(83):325-333, 1993.

[19] M. Stopford. Maritime Economics, 3rd ed. Table 13.9. Routledge, Oxford, UK, 2009.

[20] S. Wang and Q. Meng. Sailing speed optimization for container ships in a liner shipping network. Transportation Research Part E: Logistics and Transportation Review, 48(3):701-714, 2012.

[21] S. Wang and Q. Meng. Liner ship route schedule design with sea contingency time and port time uncertainty. Transportation Research Part B: Methodological, 46(5):615-633, 2012.

[22] S. Wang, Q. Meng, and Z. Liu. Bunker consumption optimization methods in shipping: A critical review and extensions. Transportation Research Part E: Logistics and Transportation Review, 53(1):49-62, 2013.

[23] S. Wang, Q. Meng, and Z. Sun. Container routing in liner shipping. Transportation Research Part E: Logistics and Transportation Review, 49(1):1 - 7, 2013. 